ANOS $\begin{aligned} & \text { Artigo convidado } \\ & \text { Versão original | Dol: http://dx.doi.org/10.1590/So034-759020210307 }\end{aligned}$

\title{
TRINTENA: UMA TRAJETÓRIA DE VIDA, LEITURA E ESCRITA COM A RAE
}

Thirty years: Life, reading and the written word with RAE

Trintena: Una trayectoria de vida, lectura y escritura con la RAE

Ana Paula Paes de Paula' | appp.ufmg@gmail.com | ORCID: 0000-0001-8035-472X

${ }^{1}$ Universidade Federal de Minas Gerais, Faculdade de Ciências Econômicas, Belo Horizonte, MG, Brasil

\section{RESUMO}

O artigo relata a trajetória da pesquisadora e sua atuação a partir da RAE nos últimos 30 anos, apresentando os principais trabalhos publicados, sua interação com colegas e a importância desse percurso, compondo uma memória que tem como objetivo informar e, quem sabe, inspirar, jovens pesquisadores (as).

PALAVRAS-CHAVE | Estudos organizacionais, trajetória profissional, trabalho editorial, escrita acadêmica, memória.

\section{ABSTRACT}

The article is a report on the researcher's career path and her activities in relation to RAE over the last 30 years. It presents the main works she has published, her interaction with colleagues and the importance of this path. This is a recollection whose aim is to inform and, who knows, to inspire young researchers.

KEYWORDS I Organization studies, career path, editorial work, academic writing, recollection.

\section{RESUMEN}

El artículo relata la trayectoria de la investigadora y su actuación a partir de la RAE, en los últimos 30 años. Al presentar los principales trabajos publicados, su interacción con colegas y la importancia de este camino, compone una memoria que tiene como objetivo informary, quién sabe, inspirar a los jóvenes investigadores.

PALABRAS CLAVE I Estudios organizacionales, trayectoria profesional, labor editorial, escritura académica, memoria. 
Meu primeiro contato com a Revista de Administração de Empresas (RAE) ocorreu ainda na graduação, por volta de 1991. Na época, eu era aluna da disciplina Comportamento Organizacional, ministrada pela Professora Cecília Bergamini no curso de Administração da FEA-USP, que nos indicou seu texto "Motivação: mitos, crenças e mal-entendidos" (Bergamini, 1990). Essa leitura inaugurou meu encantamento com a questão da subjetividade nas organizações, que permearia toda minha carreira, atingindo seu auge em 2016, quando completei minha formação teórica em Psicanálise no Círculo Psicanalítico de Minas Gerais (CPMG). A RAE passaria a fazer parte da minha vida profissional pelos 30 anos seguintes, que é metade de sua existência, considerando que a revista está completando 60 anos em 2021: a história da RAE nesse período se entrelaça com a minha própria trajetória, pois fui leitora, resenhista, autora, avaliadora, editora associada, tradutora, organizadora e participante de fóruns, sempre presente nas inovações editorais promovidas pela revista.

Em 1993, como monitora do curso de Administração, passava horas na biblioteca xerocando índices de periódicos e lendo abstracts, que era nossa forma de fazer pesquisa na época, entre eles a RAE: a coleção da FEA-USP era completa, e eu mergulhava com prazer naqueles volumes recheados de conhecimento e novos desafios. Em 1995, recém-formada e mestranda em Administração Pública na FGV EAESP, estudava os textos de Luiz Carlos Bresser-Pereira $(1983,1992)$ e acompanhava o trabalho do meu orientador, Professor Peter Kevin Spink, no Programa Gestão Pública e Cidadania (1995-2005) - leituras e experiências que fundamentaram minha dissertação de mestrado (Paula, 1998a).

Nesse mesmo ano, começava minha carreira como professora de Teoria Geral de Administração, na Fatec, que era associada à Unesp. Para compor a bibliografia das minhas disciplinas, explorava exaustivamente as páginas da $R A E$, selecionando textos clássicos como:

- “A teoria da administração é uma ideologia?”, de Maurício Tragtenberg (1971);

- “Fordismo, toyotismo e volvismo: os caminhos da indústria em busca do tempo perdido", e "Mudança organizacional: uma abordagem preliminar”, de Thomaz Wood Jr. (1992a, 1992b);

- “Controle social nas organizações”, “O poder disciplinar nas organizações formais” e "As empresas e a transmissão de ideologias”, de Fernando Prestes Motta $(1979,1981,1992)$.

Além disso, um dos livros-texto que eu utilizava nas minhas disciplinas era Introdução à Organização Burocrática (Motta \& Bresser-Pereira, 1986), de modo que posso dizer que Maurício Tragtenberg, Fernando Prestes Motta, Peter Kevin Spink e Luiz Carlos Bresser-Pereira tiveram grande influência no início da minha carreira como pesquisadora e docente.

Em meio a tantas leituras, em 1996, encontrei a oportunidade de escrever: um pequeno anúncio nas páginas da RAE recrutava resenhistas, e me voluntariei para realizar esse trabalho. Recebi da editoria o livro Third age carrers: meeting the corporate challenge, de Burnow e Fox (1994), e elaborei o texto: isso resultou no prazer de, pela primeira vez, ver um trabalho meu publicado nas páginas de um periódico acadêmico, estreando na cobiçada RAE (Paula, 1996). Do que eu não desconfiava naquele momento é que isso seria o começo uma série de resenhas que elaborei para a revista:

- O fim dos empregos, de Jeremy Rifkin (1996) (Paula, 1998b);

- A corrosão do caráter, de Richard Sennett (1999) (Paula, 2000);

- Mundo em descontrole, de Antony Giddens (2000), e Por uma outra globalização, de Milton Santos (2000) (Paula, 2001a); 
- Vida psíquica e organização, de Fernando Prestes Motta e Maria Ester de Freitas (200o), e Gestão com pessoas e subjetividade, de Eduardo Davel e Sylvia Constant Vergara (2001) (Paula, 2001b).

Essas duas últimas são resenhas críticas duplas, que nasceram de desafios colocados pela editoria da $R A E$. Um pouco mais tarde, resenharia livros de colegas da área, como José Henrique de Faria (2004) (Paula, 2004a), Martin Parker (2002) (Paula, 2004b) e Keinert, Rosa, Meneguzzo (2006) (Paula, 2007).

Terminei o mestrado na FGV EAESP em 1998 e iniciei o doutorado em Ciências Sociais no IFCH-Unicamp nesse mesmo ano, continuando minhas explorações nas áreas de Teoria das Organizações e Administração Pública. Um pouco antes, em 1997, retornei de uma viagem à Califórnia com um exemplar do Handbook of organization studies (Clegg, Hardy, \& Nord, 1996), arrematado na livraria de Stanford, e me deparei, na minha primeira participação no Encontro da Associação Nacional de Pós-Graduação em Administração (EnANPAD), nesse mesmo ano, com o Professor Miguel Caldas, da FGV EAESP, e outros colegas se organizando para a tradução desse livro, incluindo textos nacionais com comentários, que seria lançado em três volumes (Caldas, Fachin, \& Fischer, 1998, 2001, 2004). Meu interesse pelo campo dos Estudos Organizacionais e pelos estudos críticos aumentou muito no período, e alguns textos publicados pela $R A E$ me ajudaram nesse percurso:

- “Antropofagia organizacional” (Wood \& Caldas, 1998), que significou meu primeiro contato com o pensamento de Alberto Guerreiro Ramos;

“Organizações de simbolismo intensivo” (Wood, 2000), que me trouxe referências de Guy Debord e de autores que marcariam o critical management studies (Mats Alvesson, Gibson Burrel e John Hassard);

- “Fads and fashions in management” (Wood \& Caldas, 2000), que me introduziu a noção de modismos gerenciais, explorada por Eric Abrahamson.

No ano 2000, eu morava no Rio de Janeiro e frequentava a FGV EBAPE, cursando a disciplina do Professor Fernando Tenório sobre teoria crítica na pós-graduação stricto sensu, quando tive a oportunidade de ler sistematicamente a obra de Maurício Tragtenberg e Alberto Guerreiro Ramos, bem como textos clássicos da Escola de Frankfurt. Como trabalho final dessa disciplina, elaborei o texto "Tragtenberg revisitado: as inexoráveis harmonias administrativas", que foi apresentado no EnANPAD nesse mesmo ano e publicado um pouco mais tarde na Revista de Administração Pública (RAP) (Paula, 2002a).

Nesse ano, conheci o Professor Thomaz Wood Jr., da FGV EAESP: indo para o EnANPAD, fiz uma escala em São Paulo e embarquei no voo que estava a caminho de Florianópolis e, totalmente por acaso, sentei-me ao lado dele, que eu já conhecia por meio dos artigos da RAE. Para minha surpresa, ele havia lido meu texto e seria debatedor da sessão da qual eu participaria. Esse encontro deu início a uma parceria que se estendeu por alguns anos em torno de pesquisas que fizemos sobre os modismos gerenciais, denominados pop-management. Também nesse EnANPAD, tive meu primeiro contato com o Professor José Henrique de Faria, que assistiu a minha apresentação, e com o Professor Rafael Alcadipani, que iniciava sua formação acadêmica com atuação no campo dos estudos críticos em Administração, em uma intensa interlocução com Professor Fernando Prestes Motta.

$\mathrm{O}$ artigo sobre Tragtenberg foi muito bem recebido pela comunidade nesse EnANPAD, e o Professor Thomaz Wood Jr., na época, estava começando como Editor-Chefe na $R A E$. A recuperação que fiz do pensamento de Tragtenberg foi oportuna, pois estavam organizando algumas homenagens póstumas a ele, bem como um fórum na $R A E$ para discutir sua contribuição acadêmica. Recebi, então, o convite para escrever uma pensata para $R A E$ 
Documento, que foi publicada no volume 41, número 3, "Tragtenberg e a resistência da crítica: pesquisa e ensino na Administração hoje" (Paula, 2001c), ao lado dos textos de Antonio José Romera Valverde, Fernando Prestes Motta e José Henrique de Faria. Creio que, em 2001, também tivemos a oportunidade de receber o Professor Fernando Prestes Motta na FGV EBAPE para uma palestra sobre Maurício Tragtenberg, o que foi motivo de grande honra para mim, uma vez que ele fez várias referências ao artigo que eu havia apresentado no EnANPAD em 2000.

Se me recordo bem, foi também a partir de 2001 ou 2002 que me tornei avaliadora e editora associada da RAE. Nessa posição, organizei, em parceria com Peter Pelzer, o Fórum Teatro, Cinema e Organizações (Pelzer \& Paula, 2002), com artigos convidados, realizando, inclusive, a tradução para língua portuguesa de dois textos que compunham essa coletânea (Hölpl, 2002; Pelzer, 2002), tarefa que realizaria em outras oportunidades (Ford et al., 2003; Mckinley, Mone, \& Moon, 2003). Como avaliadora, ajudei muitos autores e autoras a encontrarem caminhos de aprimoramento para seus textos e, inclusive, recebi a premiação Avaliadora do Ano da Revista RAE em 2003.

O ano de 2002 também marcou o surgimento da RAE-Eletrônica, uma edição independente que publicou números por nove anos, sendo encerrada em 2010, quando a tendência de edições digitais se tornou predominante e boa parte das revistas finalizou a produção de números impressos. Para incentivar a iniciativa das edições eletrônicas, submeti um artigo que versava sobre o assédio moral e a visão de Herbert Marcuse, "Eros e narcisismo nas organizações” (Paula, 2003a), que foi aprovado e publicado no segundo volume da revista. Em 2004, o Professor Rafael Alcadipani e eu (Paula \& Alcadipani, 2004), fomos convidados a organizar, para a RAE-Eletrônica, a chamada de artigos para o Fórum Estudos Críticos em Administração, que complementou um debate efervescente no campo dos Estudos Organizacionais na época.

Em 2002, nascia também a GV-Executivo, que é publicada até hoje. Da mesma forma, como editora associada da $R A E$, fui incentivada a colaborar com a publicação, utilizando uma linguagem mais apropriada para 0 público empresarial. Participei como autora no primeiro número da revista, com o texto "Globalização questionada”, uma nova resenha do livro de Milton Santos Por uma outra globalização (Paula, 2002b). Colaborei, ainda, com o texto "Entre o desencanto e a rebeldia", abordando os dilemas da formação do administrador (Paula, 2003b), e depois com a resenha do livro de Richard Sennett (2003) Respect (Paula, 2003c).

Em 2003, conclui meu doutorado em Ciências Sociais no IFCH-Unicamp, orientado pelo Professor Reginaldo Moraes e iniciei um pós-doutorado na FGV EAESPsob a orientação do Professor Fernando Prestes Motta. Nessa época, preparava os originais da tese para um livro que seria publicado pela editora da FGV: Por uma nova gestão pública (Paula, 2005a). Além disso, encerrava um ciclo de pesquisas sobre pop-management com o Professor Thomaz Wood Jr., que gerou várias publicações, inclusive um texto sobre os mestrados profissionais em Administração brasileiros, que foi aceito pela RAE (Wood \& Paula, 2004), e iniciava a pesquisa do pós-doutorado sobre a produção em Estudos Organizacionais críticos nacionais e internacionais, bem como sobre os pensadores brasileiros críticos, enfatizando Maurício Tragtenberg e Alberto Guerreiro Ramos.

Infelizmente, o Professor Fernando Prestes Motta nos deixou em 2003, alguns meses depois de iniciada nossa parceria, e terminei o pós-doutorado sob a orientação do Professor Peter Kevin Spink. Em 2005, tive a oportunidade de fazer uma homenagem póstuma para ele na revista Organizações \& Sociedade (O\&S), com um breve texto discutindo sua tentativa de uma abordagem psicanalítica das organizações (Paula, 2005b) e a publicação de um trabalho em coautoria sobre a meia-idade, individuação e organizações, baseado no pensamento de Jung (Motta \& Paula, 2005). 
No ano de 2005, com a publicação prevista do livro Por uma nova gestão pública (Paula, 2005a), submeti à RAE um texto síntese do trabalho, "Administração Pública brasileira entre o gerencialismo e a gestão social" (Paula, 2005c), que, ao ser aprovado, veio acompanhado de uma proposta para realizar um debate: réplica do Professor Luiz Carlos Bresser-Pereira (2005) e tréplica minha (Paula, 2005d). Esse, talvez, seja um dos artigos mais citados da minha carreira acadêmica, e foi uma distinção realizar essa interlocução com Bresser-Pereira, que, ao longo dos anos, passou a sustentar uma posição muito semelhante à que eu defendia na época: a fundamental importância da participação social na gestão pública.

Foi também em 2005 que ingressei por concurso público como Professora Adjunta na Faculdade de Ciências Econômicas (FACE) da Universidade Federal de Minas Gerais (UFMG), onde permaneço até hoje, e passaria a atuar também no Centro de Pós-Graduação e Pesquisas em Administração (Cepead), depois de passar 10 anos lecionando na Fatec e em outras universidades privadas, como a Universidade Paulista (UNIP) e a Pontifícia Universidade Católica de Campinas (PucCamp). No ano de 2006, estava sendo organizada a 3 a edição especial da RAE - Minas Gerais, e tive oportunidade de contribuir com o texto "Pedagogia crítica no ensino em Administração: desafios e possibilidades” (Paula \& Rodrigues, 2006), fruto de uma parceria com o Professor Marco Aurélio Rodrigues, em uma pesquisa que realizamos junto ao Curso de Especialização em Gestão Estratégica (CEGE), que havia sido contemplado, no mesmo ano, com o prêmio de Melhor Trabalho da Divisão Ensino em Pesquisa em Administração da ANPAD.

Entre 2003 e 2006, dediquei-me à pesquisa do pós-doutorado, que deu origem a diversos artigos publicados em periódicos nacionais e também ao livro Teoria crítica nas organizações (Paula, 2008). Outro fruto dessa pesquisa foi minha última publicação na $R A E$, realizada em conjunto com a equipe que me acompanhava na época, “A tradição e a autonomia dos Estudos Organizacionais críticos no Brasil” (Paula, Maranhão, Barreto, \& Klechen, 2010), que dialogava com o trabalho dos Professores Eduardo Davel e Rafael Alcadipani, "Os estudos críticos em Administração nos anos 90" (Davel \& Alcadipani, 2003), ao incluir o levantamento dos artigos publicados também na década de 1980, demarcando a influência de autores como Maurício Tragtenberg e Alberto Guerreiro Ramos na produção nacional.

Entre 2003 e 2012, prossegui marcando posição sobre a necessidade da heterodoxia epistemológica nos Estudos Organizacionais críticos e da valorização dos pensadores nacionais (Paula, 2009). Também publiquei, a partir de uma pesquisa produtividade para o CNPQ sobre os cursos em Administração no Brasil, um dos meus livros favoritos, baseado no pensamento de Walter Benjamin: Estilhaços do real: o ensino da Administração na perspectiva benjaminiana (Paula, 2012). A RAE continuou orbitando a minha carreira, pois foi graças às provocações realizada pela série RAE Clássicos, organizada pelo Professor Miguel Caldas, que abordou a questão dos paradigmas no campo das organizações, que pude analisar a influência do livro Sociological paradigms and organisational analysis (Burrel \& Morgan, 1979) no Brasil, enquanto a área se consolidava como divisão na ANPAD, com o Encontro Nacional de Estudos Organizacionais (ENEO), criado em 2000, e a Sociedade Brasileira de Estudos Organizacionais (SBEO), que nasceu em 2011.

Essa série, RAE Clássicos, foi composta por textos de apresentação, que introduziam artigos clássicos sobre o "paradigma" em questão:

- “Paradigmas nos Estudos Organizacionais: uma introdução à série” (Caldas, 2005);

- "Paradigma funcionalista: desenvolvimento de teorias e institucionalismo nos anos 1980 e 1990 " (Caldas \& Fachin, 2005); 
- "Paradigma interpretativista: a busca da superação do objetivismo funcionalista nos anos 1980 e 1990 " (Vergara \& Caldas, 2005);

- “Teoria crítica e pós-modernismo: principais alternativas à hegemonia funcionalista” (Vieira \& Caldas, 2006).

Esse material ofereceu-me o roteiro necessário para as reflexões que dariam origem ao livro Repensando os Estudos Organizacionais: por uma nova teoria do conhecimento (Paula, 2015), publicado pela editora da FGV, que resultou da tese feita para o concurso que me elevou à categoria de Professora Titular na FACE-UFMG em 2012, no qual faço a crítica do diagrama de paradigmas de Burrel e Morgan (1979) e apresento o círculo das matrizes epistêmicas como alternativa. Influências da formação psicanalítica realizada no CPMG, abordagem que influenciou a minha carreira desde 1991, também se fizeram muito presentes, gerando a abordagem freudo-frankfurtiana que discuto nesse mesmo livro.

Paralelamente, uma busca pela ressignificação da gestão e um resgate de sua centralidade no campo dos Estudos Organizacionais foram decorrência do seminário apresentado também nesse concurso, que resultou no livro Gestão dialógica e tecnologias colaborativas, elaborado em parceria com a Professora Mariana Mayumi (Paula \& Mayumi, 2018). Nessa mesma moldura das recomendações que faço com o círculo das matrizes epistêmicas, de interlocuções entre diferentes epistemologias, realizo uma retificação de minha interlocução com o pós-estruturalismo em meu artigo mais recente: “Aproximações entre Michael Foucault e a Escola de Frankfurt: por uma abordagem pós-crítica radical para os Estudos Organizacionais” (Paula, 2020).

Com a licença do leitor e da leitora, esse percurso na minha própria trajetória fazia-se necessário para compreensão do que a RAE representou na minha carreira como jovem pesquisadora. Leitora, resenhista, autora, avaliadora, tradutora e editora associada, como eu já havia mencionado - múltiplos foram os meus papéis, e minha presença foi constante em momentos de inovação da revista. Nessa trintena, os últimos 10 anos representam um hiato na colaboração com a RAE, pois permaneci apenas como avaliadora. As transformações estruturais nos periódicos nacionais, em função do processo de internacionalização e da aceleração do fluxo de submissões, criaram mais barreiras para publicações e aumentaram significativamente o número de recusas via desk review, de modo que, apesar das pressões do ambiente produtivista, me senti mais estimulada a me dedicar à elaboração dos livros mencionados. Esse retorno às páginas da RAE em 2021 foi marcado por um convite da Editora-Chefe, Professora Maria José Tonelli, para contribuir com essa edição comemorativa de 60 anos, a fim de inspirar jovens pesquisadores (as), em um reconhecimento da minha constante colaboração com a $R A E$ - convite que aceitei com alegria e prazer.

Na minha trajetória, sem dúvida, a RAE fez toda a diferença, pois foi uma escola onde aprendi a ler, escrever e editar criticamente. Sou imensamente grata pelas oportunidades que tive e pelo reconhecimento dos meus méritos, o que me possibilitou ver meu nome ao lado de pesquisadores pelos quais tenho grande respeito e admiração, deslocando-me da posição de leitora para a de coautora, debatedora e parceira. Realmente espero que não somente a $R A E$, mas todos os periódicos nacionais encontrem espaço de resistência diante do novo cenário que se configura no Brasil para a produção de artigos científicos, pois será uma vitória continuar vendo a perpetuação de inovações e da ousadia editorial, bem como textos de jovens talentosos (as) pesquisadores (as) se tornarem clássicos, desenvolvendo-se ao longo do tempo e dando notícias de seu aprimoramento intelectual e acadêmico. 


\section{REFERÊNCIAS}

Bergamini, C. W. (1990). Motivação: Mitos, crenças e malentendidos. RAE-Revista de Administração de Empresas, 30(2), 23-34. doi: 10.1590/So034-75901990000200003

Bresser-Pereira, L. C. (1983). Os limites da 'abertura' da sociedade civil. RAE-Revista de Administração de Empresas, 23(4), 5-14.

Bresser-Pereira, L. C. (1992). Desenvolvimento econômico e empresário. RAE-Revista de Administração de Empresas, 32(3), 6-12. doi: 10.1590/So034-75901992000300002

Bresser-Pereira, L. C. (2005). Réplica: comparação impossível. RAE-Revista de Administração de Empresas, 45(1), 50-51. doi: 10.1590/So034-75902005000100006

Burnow, B., \& Fox, J. M. (1994). Third age carrers: Meeting the corporate challenge. England: Glower.

Burrel, G., \& Morgan, G. (1979). Sociological paradigms and organisational analysis: Elements of the sociology of corporate life. Vermont: Ashgate.

Caldas, M. (2005). Paradigmas nos estudos organizacionais: Uma introdução à série. RAE-Revista de Administração de Empresas, 45(1), 53-57. doi: 10.1590/So034-75902005000100008

Caldas, M., \& Fachin, R. (2005). Paradigma funcionalista: Desenvolvimento de teorias e institucionalismo nos anos 1980 e 1990. RAE-Revista de Administração de Empresas, 45(2), 46-51. doi: 10.1590/So034-75902005000200005

Caldas, M., Fachin, R., \& Fischer, T. (Orgs.). (1998). Handbook de estudos organizacionais (Vols. 1-3). São Paulo, SP: Atlas.

Clegg, S., Hardy, C., \& Nord, W. (Eds.). (1996). Handbook of organization studies. London, UK; Thousand Oaks, New Delhi, India: Sage.

Davel, E., \& Alcadipani, R. (2003). Estudos críticos em administração: A produção científica brasileira nos anos 1990. RAE-Revista de Administração de Empresas, 43(4), 72 85. doi: 10.1590/So034-75902003000400006

Davel, E., \& Vergara, S. C. (2001). Gestão com pessoas $e$ subjetividade. São Paulo, SP: Atlas.

Faria, J. H. (2004). Economia política do poder (Vols. 1-3). Curitiba, PR: Juruá.

Ford, E. W., Ducan, J. W., Bedeian, A. G., Ginter, P. M., Rousculp, M. D., \& Adams, A. (2003). A pesquisa que faz a diferença. RAE-Revista de Administração de Empresas, 43(4), 86-101.

Giddens, A. (2000). Mundo em descontrole: O que a globalização está fazendo por nós. Rio de Janeiro, RJ: Record.

Hölpl, H. (2002). Vertigo e o sublime trágico. RAE-Revista de Administração de Empresas, 42(4), 47-56. doi: 10.1590/ So034-75902002000400006

Keinert, T., Rosa, T. E. C., \& Meneguzzo, M. (2006). Inovação e cooperação intergovernamental: Microrregionalização, consórcios, parcerias e terceirização no setor da saúde. São Paulo, SP: Annablume.
Mckinley, W., Mone, M. A., \& Moon, G. (2003). Determinantes e desenvolvimento de escolas na teoria organizacional. RAERevista de Administração de Empresas, 43(3), 85-99.

Motta, F. C. P. (1979). Controle social nas organizações. RAERevista de Administração de Empresas, 19(3), 11-25. doi: 10.1590/S0034-75901993000500005

Motta, F. C. P. (1981). O poder disciplinar nas organizações formais. RAE-Revista de Administração de Empresas, 21(4), 33-41.

Motta, F. C. P. (1992). As empresas e a transmissão da ideologia. RAE-Revista de Administração de Empresas, 32(5), 38-47.

Motta, F. C. P. (2005). Réplica: Comparação impossível. RAERevista de Administração de Empresas, 45(1), 50-51. doi: 10.1590/So034-75902005000100006

Motta, F. C. P., \& Freitas, M. E. (2000). Vida psíquica e organização. Rio de Janeiro, RJ: Editora FGV.

Motta, F. C. P., \& Paula, A. P. P. de. (2005). Meia-idade, individuação e organizações. Organizações \& Sociedade, 12(34), 17-30. doi: 10.1590/S1984-92302005000300002

Motta, F. C. P., \& Bresser-Pereira, L. C. (1986). Introdução à organização burocrática. São Paulo, SP: Brasiliense.

Parker, M. (2002). Against management: Organization in the age of managerialism. Cambrigde: Polity.

Paula, A. P. P. de. (1996). Third age careers: meeting the corporate challenge. RAE-Revista de Administração de Empresas, 36(2), 70-73. doi: 10.1590/So034-75901996000300009

Paula, A. P. P. de. (1998a). Reinventando a democracia: ONGs e movimentos sociais na construção de uma nova gestão pública, Dissertação de Mestrado. FGV EAESP, São Paulo, SP.

Paula, A. P. P. de. (1998b). O fim dos empregos: O declínio inevitável dos níveis dos empregos e a redução da força global de trabalho. RAE-Revista de Administração de Empresas, 38(2), 75-76. doi: 10.1590/So034-75901998000200009

Paula, A. P. P. de. (2000). A corrosão do caráter: Conseqüências pessoais do trabalho no novo capitalismo. RAE-Revista de Administração de Empresas, 40(3), 101-103. doi: 10.1590/ So034-75902000000300011

Paula, A. P. P. de. (2001a). Mundo em descontrole/Por uma outra globalização [Resenha]. RAE-Revista de Administração de Empresas, 41(3), 96-97. doi: 10.1590/So03475902001000300014

Paula, A. P. P. de. (2001b). Vida psíquica e organização/Gestão com pessoas e subjetividade [Resenha]. RAE-Revista de Administração de Empresas, 41(4), 103-104. doi: 10.1590/ So034-75902001000400012

Paula, A. P. P. de. (2001c). Tragtenberg e a resistência da crítica: Pesquisa e ensino da administração hoje. RAE-Revista de Administração de Empresas, 41(3), 77-81. doi: 10.1590/ So034-75902001000300010 
Paula, A. P. P. de. (2002a). Tragtenberg revisitado: As inexoráveis harmonias administrativas e a burocracia flexível. RAE-Revis ta de Administração Pública, 36(1), 127-144. Retrieved from http://bibliotecadigital.fgv.br/ojs/index.php/rap/article/ view/6431

Paula, A. P. P. de. (2002b). Globalização questionada. GVExecutivo, 1(1), 90-91. Retrieved from https://rae.fgv.br/sites/ rae.fgv.br/files/artigos/1538.pdf

Paula, A. P. P. de. (2003a). Eros e narcisismo nas organizações. RAE-Eletrônica, 2(2), 1-12. Retrieved from https://rae.fgv. $\mathrm{br} / \mathrm{rae}$-eletronica/vol2-num2-2003/eros-narcisismo-nasorganizacoes

Paula, A. P. P. de. (2003b). Entre o desencanto e a rebeldia. GVExecutivo, 2(1), 84-88. Retrievied from: https://rae.fgv.br/ sites/rae.fgv.br/files/artigos/1775.pdf

Paula, A. P. P. de. (2003c). Respeito em evidência. GV-Executivo, 2(3), 94-95. Retrievied from https://rae.fgv.br/gv-executivo/ vol2-num3-2003/respeito-em-evidencia

Paula, A. P. P. de. (2004a). Repensando os estudos críticos em administração [Resenha]. RAE-Revista de Administração de Empresas, 44(2), 114-115. doi: 10.1590/So03475902004000200011

Paula, A. P. P. de. (2004b). Novas formas de poder e controle nas organizações. RAE-Revista de Administração de Empresas, 45(3), 122-123. Recuperado de https://www.fgv.br/rae/ artigos/revista-rae-vol-45-num-3-ano-2005-nid-46361

Paula, A. P. P. de. (2005a). Por uma nova gestão pública: Limites e potencialidades da experiência contemporânea. Rio de Janeiro, RJ: Editora FGV.

Paula, A. P. P. de. (2005b). Fernando Prestes Motta: Em busca de uma abordagem psicanalítica das organizações. Organizações \& Sociedade, 12(34), 13-15. doi: 10.1590/ S1984-92302005000300001

Paula, A. P. P. de. (2005c). Administração Pública brasileira entre o gerencialismo e a gestão social. RAE-Revista de Administração de Empresas, 45(1), 36-49. doi: 10.1590/ So034-75902005000100005

Paula, A. P. P. de. (2005d). Tréplica: Comparação possível. RAE Revista de Administração de Empresas, 45(1), 51-52. doi: 10.1590/So034-75902005000100007

Paula, A. P. P. de. (2007). Cooperação e inovação na gestão pública: O caso da saúde. RAE-Revista de Administração de Empresas, 47(2), 124-125. doi: 10.1590/So03475902007000200009

Paula, A. P. P. de. (2008). Teoria crítica nas organizações. São Paulo, SP: Thomson Learning.

Paula, A. P. P. de. (2009). Ser ou não ser, eis a questão: A crítica aprisionada na Caverna de Platão. Cadernos EBAPE.BR, 7(3), 492-503. Recuperado de http://bibliotecadigital.fgv.br/ojs/ index.php/cadernosebape/article/view/5394/4128

Paula, A. P. P. de. (2012). Estilhaços do real: O ensino da administração na perspectiva benjaminiana. Curitiba, PR: Juruá.
Paula, A. P. P. de. (2015). Repensando os estudos organizacionais: Por uma nova teoria do conhecimento. Rio de Janeiro, RJ: Fapemig, Editora FGV.

Paula, A. P. P. de. (2020). Aproximações entre Michel Foucault e a Escola de Frankfurt: Por uma abordagem pós-crítica radical para os estudos organizacionais. Organizações \& Sociedade, 27(95), 705-725. doi: 10.1590/1984-9270954

Paula, A. P. P. de, \& Alcadipani, R. (2004). Fórum Estudos Críticos em Administração [Apresentação]. RAE-Eletrônica, 3(2), 1-5. Recuperado de https://rae.fgv.br/rae-eletronica/ vol3-num2-2004/apresentacao-forum-estudos-criticos-emadministracao

Paula, A. P. P. de, Maranhão, C. S., Barreto, R., \& Klechen, C. (2010). A tradição e a autonomia dos estudos organizacionais críticos no Brasil. RAE-Revista de Administração de Empresas, 50(1), 10-23. Recuperado de https://www.scielo.br/pdf/rae/ v50n1/a02v5on1.pdf

Paula, A. P. P. de, \& Mayumi, M. (2018). Gestão dialógica e tecnologias colaborativas. Curitiba, PR: Appris.

Paula, A. P. P. de, \& Rodrigues, M. A. (2006). Pedagogia crítica no ensino da administração: Desafio e possibilidades. RAE-Revista de Administração de Empresas, 46(Edição Especial Minas Gerais), 10-22. doi: 10.1590/So034 75902006000500001

Pelzer, P. (2002). Dead man: Um encontro com um passado desconhecido. RAE-Revista de Administração de Empresas, 42(4), 36-46. doi: 10.1590/S0034-75902002000400005

Pelzer, P., \& Paula, A. P. P. de. (2002). Fórum Teatro, Cinema e Organizações [Apresentação]. RAE-Revista de Administração de Empresas, 42(4), 10. Recuperado de https://rae.fgv.br/ sites/rae.fgv.br/files/10.1590_s0034-75902002000400005a. pdf

Rifkin, J. (1996). O fim dos empregos: O declínio inevitável dos niveis dos empregos e a redução da força global de trabalho. São Paulo, SP: Makron Books.

Santos, M. (2000). Por uma outra globalização: Do pensamento único à consciência universal. Rio de Janeiro, RJ: Record.

Sennett, R. (1999). A corrosão do caráter: Consequências pessoais do trabalho no novo capitalismo. Rio de Janeiro, RJ: Record.

Sennett, R. (2003). Respect. In a world of inequality. New York, London: W. W. Norton.

Tragtenberg, M. (1971). A teoria da administração é uma ideologia? RAE-Revista de Administração de Empresas, 11(4), 7-21. Recuperado de https://rae.fgv.br/rae/vol11-num4-1971/ teoria-geral-administracao-ideologia

Vergara, S. C., \& Caldas, M. (2005). Paradigma interpretativista: A busca da superação do objetivismo funcionalista nos anos 1980 e 1990. RAE-Revista de Administração de Empresas, 45(4), 66-72. doi: 10.1590/S0034-75902005000400006

Vieira, M., \& Caldas, M. (2006). Teoria crítica e pós-modernismo: Principais alternativas à hegemonia funcionalista. $R A E$ Revista de Administração de Empresas, 46(1), 59-70. doi: 10.1590/S0034-75902006000100006 
Wood, T., Jr. (1992a). Fordismo, toyotismo e volvismo: Os caminhos da indústria em busca do tempo perdido. RAERevista de Administração de Empresas, 32(4), 6-18. doi: 10.1590/S0034-75901992000400002

Wood, T., Jr. (1992b). Mudança organizacional: Uma abordagem preliminar. RAE-Revista de Administração de Empresas, 32 (4), 74-87. doi: 10.1590/So034-75901992000300009

Wood, T., Jr. (2000). Organizações de simbolismo intensivo. RAE-Revista de Administração de Empresas, 40(1), 20-28. doi: 10.1590/So034-75902000000100003
Wood, T., Jr., \& Caldas, M. (1998). Antropofagia organizacional. RAE-Revista de Administração de Empresas, 38(4), 6-7. doi: 10.1590/So034-75901998000400002

Wood, T., Jr., \& Caldas, M. (2000). Fads and fashion in management: The case of ERP. RAE-Revista de Administração de Empresas, 40(3), 8-17. doi: 10.1590/So03475902001000400012

Wood, T., Jr., \& Paula, A. P. P. de. (2004). O fenômeno dos MPAs brasileiros: Hibridismo, diversidade e tensões. RAE-Revista de Administração de Empresas, 44(1), 116-129. doi: 10.1590/ So034-75902004000100007

\section{CONTRIBUIÇÃO DA AUTORA}

A autora declara que realizou todas as etapas de desenvolvimento do estudo. Desde a conceitualização e abordagem teórica-metodológica, a revisão teórica (levantamento de literatura) e, por fim, redação e revisão final do artigo. 